\title{
Evaluation of CDC light traps for mosquito surveillance in a malaria endemic area on the Thai-Myanmar border
}

Patchara Sriwichai ', Stephan Karl², Yudthana Samung ${ }^{1}$, Suchada Sumruayphol', Kirakorn Kiattibutr ${ }^{1,5}$, Anon Payakkapol ${ }^{1}$, Ivo Mueller ${ }^{2}$, Guiyun Yan ${ }^{3}$, Liwang Cui ${ }^{4}$ and Jetsumon Sattabongkot ${ }^{5^{*}}$

\begin{abstract}
Background: Centers for Disease Control and Prevention miniature light traps (CDC-LT) baited with $\mathrm{CO}_{2}$ are a routine tool for adult mosquito sampling used in entomological surveys, and for monitoring and surveillance of disease vectors. The present study was aimed at evaluating the performance of baited and unbaited CDC-LT for indoor and outdoor trapping of endemic mosquito species in northwestern Thailand.

Methods: CDC-LT $(n=112)$ with and without dry ice baits were set both indoors and outdoors in 88 selected houses for stretches of 5 consecutive nights per month in 7 villages in Tha Song Yang district, Tak province between January 2011 and March 2013. Individual traps were repeatedly placed in the same location for a median of 6 (range 1-10) times. Mosquitoes were identified by morphological characteristics and classified into blood-fed, empty, male/female and gravid. Absolute mosquito numbers were converted to capture rates (i.e., mosquitoes per trap and year). Capture rates were compared using multilevel negative binomial regression to account for multiple trap placements and adjust for regional and seasonal differences.

Results: A total of 6,668 mosquitoes from 9 genera were collected from 576 individual CDC-LT placements. Culex was the predominant captured genus (46\%), followed by anopheline mosquitoes (45\%). Overall, $\mathrm{CO}_{2}$ baited traps captured significantly more Culex (especially Culex vishnui Theobald) and Anopheles mosquitoes per unit time (adjusted capture rate ratio (aCRR) 1.64 and 1.38, respectively). Armigeres spp. mosquitoes were trapped in outdoor traps with significantly higher frequency (aCRR: 1.50), whereas Aedes albopictus (Skuse) had a tendency to be trapped more frequently indoors (aCRR: 1.89, $p=0.07$ ). Furthermore, capture rate ratios between $\mathrm{CO}_{2}$ baited and non-baited CDC-LT were significantly influenced by seasonality and indoor vs. outdoor trap placement.

Conclusion: The present study shows that CDC-LT with $\mathrm{CO}_{2}$ baiting capture significantly more Culex and Anopheles mosquitoes, some of which (e.g., Cx. vishnui, Cx. quinquefasciatus Say, An. minimus s.l. Theobald, An. maculatus s.l. Theobald) represent important disease vectors in Thailand. This study also shows significant differences in the capture efficiency of CDC-LT when placed indoors or outdoors and in different seasons. Our study thus provides important guidelines for more targeted future vector trapping studies on the Thai-Myanmar border, which is an important cross-border malaria transmission region in Thailand.
\end{abstract}

Keywords: CDC light trap, Dry ice, $\mathrm{CO}_{2}$, Anopheles, Culex, Aedes, Malaria, Thailand

\footnotetext{
*Correspondence: jetsumon.pra@mahidol.edu

${ }^{5}$ Mahidol Vivax Research Unit, Faculty of Tropical Medicine, Mahidol

University, Bangkok, Thailand

Full list of author information is available at the end of the article
}

\section{Biomed Central}

(C) 2015 Sriwichai et al. Open Access This article is distributed under the terms of the Creative Commons Attribution 4.0 International License (http://creativecommons.org/licenses/by/4.0/), which permits unrestricted use, distribution, and reproduction in any medium, provided you give appropriate credit to the original author(s) and the source, provide a link to the Creative Commons license, and indicate if changes were made. The Creative Commons Public Domain Dedication waiver (http://creativecommons.org/publicdomain/zero/1.0/) applies to the data made available in this article, unless otherwise stated. 


\section{Background}

Collection and speciation of adult mosquitoes is important in entomological studies monitoring disease vectors, especially in malaria endemic regions [1]. Field studies that aim at describing the interactions of vectors with pathogens, human hosts and the environment help to understand region-specific transmission dynamics and disease spread, and guide efforts to control and eliminate diseases. While malaria is now absent from large parts of Thailand, it is still an important health problem in some border regions, particularly the northwestern border region with Myanmar. Tak province, Northwestern of Thailand, had a malaria incidence rate of 11.7 cases per 1,000 people in 2013 [2]. Malaria elimination programs are expected to make $80 \%$ of Thailand malaria-free by 2020 [3]. To achieve this goal, welldeveloped and continuous surveillance programs in the border regions with Cambodia and Myanmar are required in order to quantify and control cross-border malaria transmission [4]. In this context, entomological surveillance plays an important role.

Human landing catches (HLC) are the standard method to study vector bionomics, as this technique is focused on host-seeking mosquitoes that may represent the most relevant proportion of the mosquito population for disease transmission [5]. However, the HLC approach is ethically controversial, particularly as the study-related risk of infection of the exposed individuals cannot be completely abrogated [1]. Furthermore HLC are labor intensive and difficult to standardize due to variation in individual attractiveness to mosquitoes and variation in the experience of individuals performing HLC assays [1].

A variety of alternative sampling and analysis methods have previously been studied in terms of their field efficiency and applicability, which depends on local vector populations [6, 7]. Odor-baited entry traps are a practical alternative to HLC for adult collection and CDCLT are one of the most widely-used type of trap, and can be used for indoor and outdoor collection [1]. Several previous studies have shown statistically significantly better trapping results with $\mathrm{CO}_{2}$-baited CDC-LT [8-10], especially for Culex species. Specifically, increasing levels of $\mathrm{CO}_{2}$ (dissipated either by the sublimation of dry ice or from $\mathrm{CO}_{2}$ cylinders), up to a threshold of approximately $500 \mathrm{~mL} / \mathrm{min}$ have been observed to be related with better trapping efficiency and higher numbers of trapped mosquitoes [11]. However, other studies have shown no difference in trapping efficiency for Anopheles adult female mosquitoes [12-14]. These mixed results and the fact that there have been very few studies on the effectiveness of CDC-LT in Thailand [14] warrant further investigations, especially since many previous studies lack multivariate analyses of factors that may influence trapping efficiency such as whether a trap was placed indoors or outdoors, geographic region, season of the year and feeding status of mosquitoes.

The present study was conducted in order to evaluate mosquito sampling by CDC-LT in 7 villages in northwestern Thailand and to analyze relative trap efficiency for traps augmented with $\mathrm{CO}_{2}$ baits and placed either indoors or outdoors. The region is one of the most malaria endemic areas in Thailand. There are typically two peaks in malaria case frequency, the first in the rainy season (May-July) and the second in the beginning of dry season during October to November [15]. The region is environmentally and demographically very diverse, endemic to both Plasmodium falciparum and $P$. vivax and home to a diversity of anopheline vector species making it a very complex malaria transmission environment. [4, 15-17]. This study was done mainly in order to identify the best conditions to trap specific potential vectors but also to further learn about the behavioral differences and preferences of different vectors of malaria and other vector-borne diseases and their distribution and abundance in this area. Our study shows important differences in trapping efficiency for different mosquito genera and species present in northwestern Thailand. The results are therefore useful for the planning of further, larger trapping studies and routine entomological surveillance programs, which would benefit from maximizing capture efficiency for potential disease vectors.

\section{Methods \\ Study site}

Adult mosquitoes were collected using CDC-LT with and without $\mathrm{CO}_{2}$ baits in 7 villages in Tak Province, Thailand, located along the Thai-Myanmar border (Fig. 1), namely: Mae Usu, Tae Nu Ko, Mae Plu, Tha Song Yang, Suan Oi, Tala Oka and Nong Bua. Weather in the area is characterized by three seasons: hot (March to May), wet (June to August) and dry (September to February). Mean annual rainfall in the study period was $171.05 \mathrm{~mm}$ (range: 0 to $535 \mathrm{~mm}$ ), mean annual temperature was $26.6{ }^{\circ} \mathrm{C}$ (range: 24.1-28.0 ${ }^{\circ} \mathrm{C}$ ), and mean humidity was $72 \%$ (range: 59-88 \%). There are approximately 138,000 residents living in approximately 27,000 houses in these villages. Most people farm seasonal crops and rice, and engage in forestry work. The population is a mix of local Thai and either permanent or temporary Karen migrants from Myanmar. Most of the houses where traps were placed $(n=88)$ were located near a river and/or swamp areas, which are likely to represent mosquito breeding habitats.

According to Ministry of Public Health policy, vector control is being carried out in all active transmission areas, including the study area. Policy recommends that in-house residual spraying (IRS) is conducted twice a year in perennial transmission areas, and annually in 


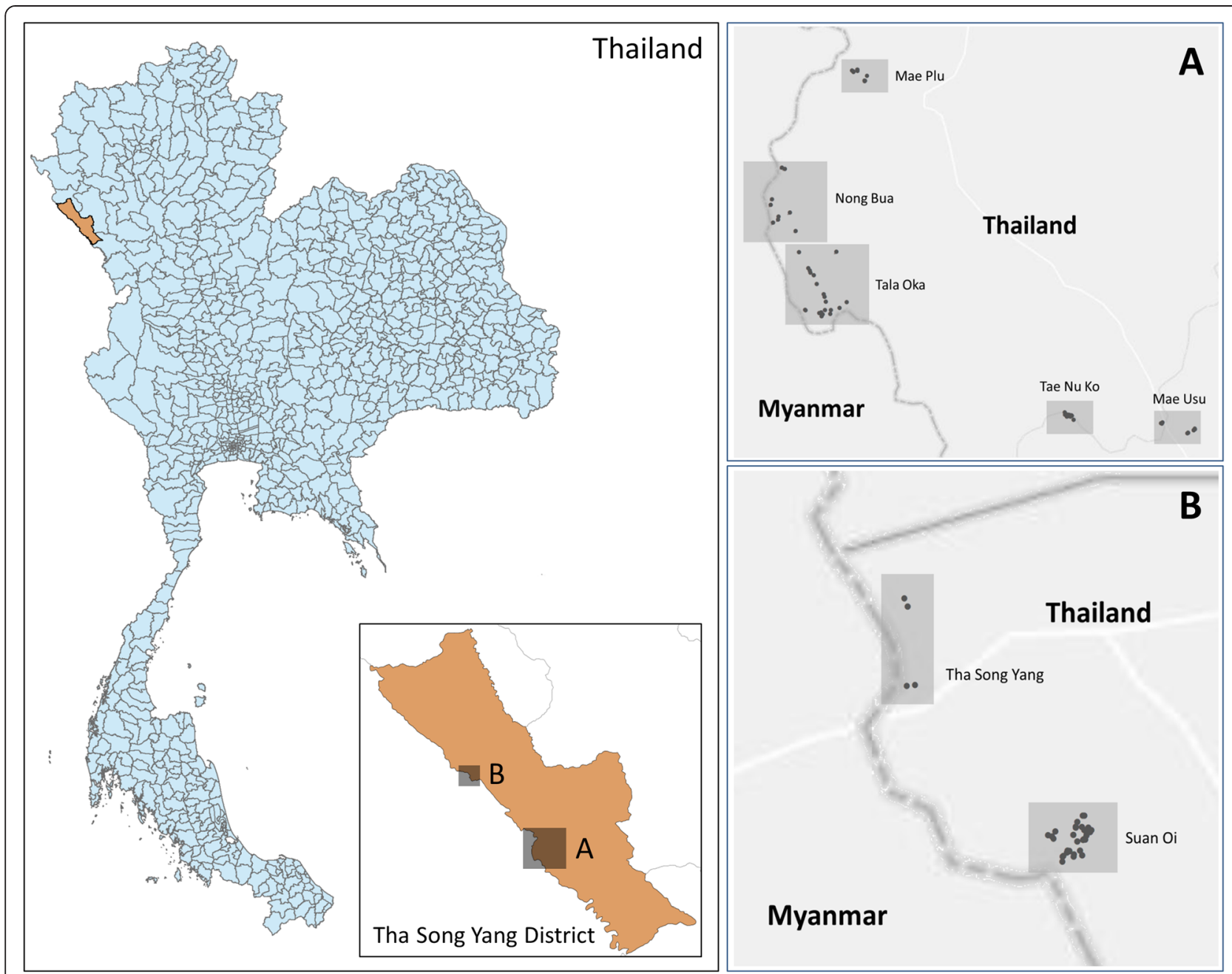

Fig. 1 Map of the study sites. The left panels show the location of Tha Song Yang district, Tak province within Thailand and the location of the study regions (a and $\mathbf{b}$ ). The right panels provide a more detailed view of the study sites. Mosquitoes were collected in 7 selected villages: Mae Usu, Tae Nu Ko, Mae Plu, Tha Song Yang, Suan Oi, Tala Oka and Nong Bua between Jan 2012 and Mar 2013. Data were aggregated by region (a and $\mathbf{b})$

periodic transmission areas covering the transmission season. In addition, permethrin insecticide treated nets (ITN) are distributed in high transmission areas and are offered (free of charge) by the malaria clinics. Thermal fogging is applied during malaria outbreaks once a week for 4 consecutive weeks. Among the selected houses, we found a surprisingly low actual ITN usage: only $50 \%$ Thai houses and $30 \%$ temporal Karen houses reported to use ITNs when asked before setting the traps.

\section{Study design and mosquito collection}

CDC-LT ( $n=112$, BioQuip model 2836BQ, with a 6 volt battery, USA) were placed inside or around 88 selected houses for stretches of five consecutive nights from January 2011 to March 2013. These stretches of 5 nights are from now on referred to as 'trap placements'. There were a total of 576 trap placements corresponding to
2,880 trap-nights in the study period. Trap coverage varied between villages from 65 trap-nights in Tha Song Yang to 1,330 trap-nights in Suan Oi (Additional file 1: Table S2), and by season, from 55 trap-nights in February to 440 trap-nights in May. The traps were not placed in December. Because of this variation in sampling density, data were aggregated into 2 regions (north (A) and south (B) as indicated in Fig. 1) and into the 3 seasons (dry: September to February, hot: March to May and wet: June to August). The traps were installed by hanging them approximately $1.5 \mathrm{~m}$ above the ground either indoors (usually in the living room and some houses have only a single room) or outdoors (10-20 m away from houses, see Fig. 2). Approximately half of the traps (corresponding to a total of 1,600 trap-nights) were augmented with $1 \mathrm{~kg}$ of dry ice whereas the remaining traps (corresponding to a total of 1,280 trap nights) had 


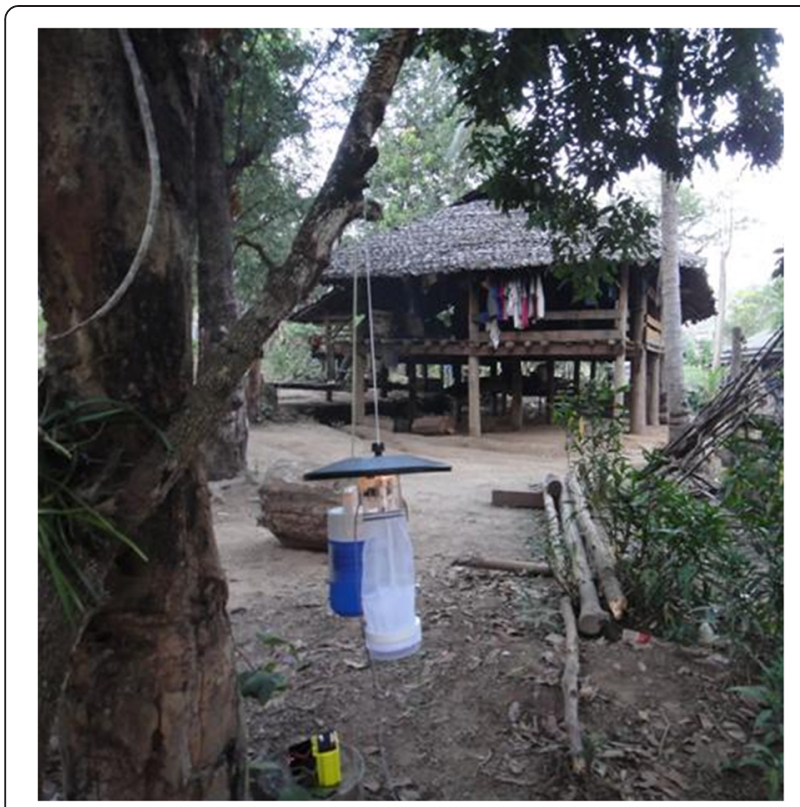

Fig. 2 CDC light trap setting. The CDC light traps with and without $1 \mathrm{~kg}$ of dry ice were set by hanging them in about 1.5 meter height either indoors and outdoors (10-20 meters from house), overnight (6.00 pm.-6.00 am.). Mosquitoes were collected daily in the early morning

no dry ice. The locations of the traps were recorded by GPS (Garmin GPSMAP 60CSx, USA). Mosquitoes were collected from the traps each morning and sent to the laboratory (Department of Medical Entomology, Faculty of Tropical Medicine, Mahidol University, Bangkok) for analysis. Mosquito species were determined based on morphological characteristics [18-21]. Mosquito blood meal status (empty, blood fed, half gravid, and gravid) was also recorded.

\section{Data analysis}

Statistical analyses were performed in Stata 12 (StataCorp, USA). Absolute mosquito numbers were converted to mosquito capture rates, i.e., mosquitoes per trap per year (MTY). As the same traps were placed multiple times, multivariate analysis was conducted by multilevel negative binomial regression to account for overdispersion of the counts. Fixed effects were $\mathrm{CO}_{2}$ vs. no $\mathrm{CO}_{2}$, indoor vs. outdoor placement, region and season. Analyses were repeated for each relevant mosquito genus (Culex, Anopheles, Armigeres, Aedes) and species (An. minimus s.l., An. maculatus s.l., An. annularis s.l. van der Wulp, Cx. vishnui, Cx. quinquefasciatus, Ae. albopictus), as well as for blood-fed mosquitoes only in cases where trapped mosquito numbers allowed for this analysis. Effect measure modification was tested for by including interaction terms for trap placement (indoor/outdoor) and season as well as for trap type $\left(\mathrm{CO}_{2} /\right.$ non- $\left.-\mathrm{CO}_{2}\right)$ and season.

\section{Results}

\section{Mosquito trapping}

A total of 6,668 adult mosquitoes were collected in a total of 576 individual CDC-LT placements (2,880 trap-nights). A summary of the absolute numbers of mosquitoes captured per trap-type and indoor vs. outdoor placement is given in Table 1 and an overview over the most abundant mosquito species captured in this study is shown in Fig. 3. There were 42 species that represented less than $1 \%$ of the total captured population and these are summarized as 'others'. A table showing all capture data, including minority species, mosquito feeding and gravidity status, is presented in the (Additional file 2: Table S1). Culex spp. were predominant ( $46 \%$ of the total collected mosquitoes were Culex spp.). The main Culex species were $C x$. vishnui $(n=977), C x$. fuscocephala Theobald $(n=951)$, $C x$. pseudovishnui Colless $(n=366)$, and $C x$. quinquefasciatus $(n=201)$ (Fig. 3). Forty-five percent (45 \%) of captured mosquitoes were Anopheles spp. with $A n$. minimus s.l. $(n=1206)$, An. maculatus s.l. $(n=641)$, and $A n$. annularis s.l. $(n=431)$ as the most abundant species (Table 1, Fig. 3, Additional file 2: Table S1). Other important genera were Armigeres spp. $(n=404)$ where Ar. subalbatus (Coquillett) $(n=392)$ represented the vast majority and Aedes spp. mosquitoes with Ae. albopictus $(n=68)$ and Ae. aegypti (Linneaus) $(n=31)$ as the main representatives.

Most of the collected mosquitoes were female (94.4\%) and in the empty stage $(94.0 \%)$. The ratio of blood-fed mosquitoes varied between species with $C x$. vishnui (1.3\%), Cx. quinquefasciatus (1.5\%), An. minimus s.l. (13\%), An. maculatus s.l. (7\%), An. annularis s.l. (4\%), Ae. aegypti (50\%), and Ae. albopictus (8\%) collected as blood-feds. Table 2 shows the multivariate analysis results of mosquito capture rate for the main vector genera and species detected in this study.

Anopheles spp. mosquitoes tended to be captured more efficiently in $\mathrm{CO}_{2}$-baited traps (adjusted capture rate ratio (aCRR) 1.39, $P=0.04$ ). This trend became statistically insignificant when the main Anopheles species were analyzed separately (An. minimus s.l. aCRR: $1.27, P=0.11 ; A n$. maculatus s.l. aCRR: $1.28, P=0.18, A n$. annularis s.l. aCRR: 1.28 , $P=0.37)$. In addition, $A n$. minimus s.l. was captured more frequently indoors (aCRR for outdoors: 0.71, $P=0.02$ ).

Overall, Culex species were trapped in the $\mathrm{CO}_{2}$ baited traps with similar efficiency as in the non-baited traps. However, there was a significant difference when the analysis was restricted to $C x$. vishnui (aCRR: $1.64, P=0.02$ ). Armigeres spp. mosquitoes were captured more frequently outdoors (aCRR: 1.5, P=0.02) whereas Ae. albopictus tended to be captured more frequently indoors (aCRR for outdoor traps $0.53, p=0.07$ ). No differences in these trends were found when only the blood-fed mosquitoes were analyzed. 
Table 1 Numbers of adult mosquitoes collected indoors and outdoors and using CDC-LT with and without $\mathrm{CO}_{2}$

\begin{tabular}{|c|c|c|c|c|c|c|c|c|}
\hline \multirow[t]{2}{*}{ Genus } & \multicolumn{2}{|c|}{ LT with $\mathrm{CO}_{2}$} & \multirow[t]{2}{*}{ Sum $\left(\mathrm{CO}_{2}\right)$} & \multicolumn{2}{|c|}{ LT without $\mathrm{CO}_{2}$} & \multirow[t]{2}{*}{$\operatorname{Sum}\left(\mathrm{W} / \mathrm{O} \mathrm{CO}_{2}\right)$} & \multirow[t]{2}{*}{ Total } & \multirow[t]{2}{*}{$\%$ total } \\
\hline & Indoor & Outdoor & & Indoor & Outdoor & & & \\
\hline Culex & 851 & 1120 & 1971 & 823 & 299 & 1122 & 3093 & 46.39 \\
\hline Anopheles & 843 & 988 & 1831 & 784 & 373 & 1157 & 2988 & 44.81 \\
\hline Armigeres & 73 & 164 & 237 & 101 & 58 & 159 & 396 & 5.94 \\
\hline Aedes & 43 & 46 & 89 & 52 & 19 & 71 & 160 & 2.40 \\
\hline Uranotaenia & 1 & 2 & 3 & 7 & 3 & 10 & 13 & 0.19 \\
\hline Mansonia & 4 & 0 & 4 & 4 & 0 & 4 & 8 & 0.12 \\
\hline Topomyia & 1 & 0 & 1 & 3 & 1 & 4 & 5 & 0.07 \\
\hline Ficalbia & 0 & 0 & 0 & 0 & 3 & 3 & 3 & 0.04 \\
\hline Aedeomyia & 0 & 0 & 0 & 2 & 0 & 2 & 2 & 0.03 \\
\hline Total & 1816 & 2320 & 4136 & 1776 & 756 & 2532 & 6668 & \\
\hline
\end{tabular}

\section{Effect measure modification by indoor vs. outdoor} placement

Whether the traps were placed inside houses or outdoors played a significant role. $\mathrm{CO}_{2}$ baited traps performed better for anopheline mosquitoes than unbaited traps in outdoor locations (aCRR 1.56, $P=0.02$ ) but performed similarly well in indoor locations (aCRR: 1.14, $P=0.41$ ). This may be explained by the presence of occupants indoors representing bait and thus enhancing the efficiency of CDC-LT even without $\mathrm{CO}_{2}$. Similarly, Culex mosquitoes had a tendency to be captured better in the $\mathrm{CO}_{2}$ baited traps than in the unbaited traps in outdoor locations (aCRR 1.49; $P=0.07$ ), while the indoor baited traps performed similar to the indoor non-baited traps (aCRR 1.01; $P=0.96$ ) and thus the overall effect was not significant (Table 2). Armigeres spp. were also captured significantly better in $\mathrm{CO}_{2}$ baited traps placed outdoors than in the non-baited traps placed outdoors (aCRR 2.17, $P=0.01$ ), but tended to be captured less well in the $\mathrm{CO}_{2}$ baited traps placed indoors (aCRR 0.71; $P=0.10)$.

\section{Effect measure modification by seasonality}

We have previously shown strong, species-specific seasonality in mosquito abundance in this region [22]. Therefore, effect measure modification of trapping

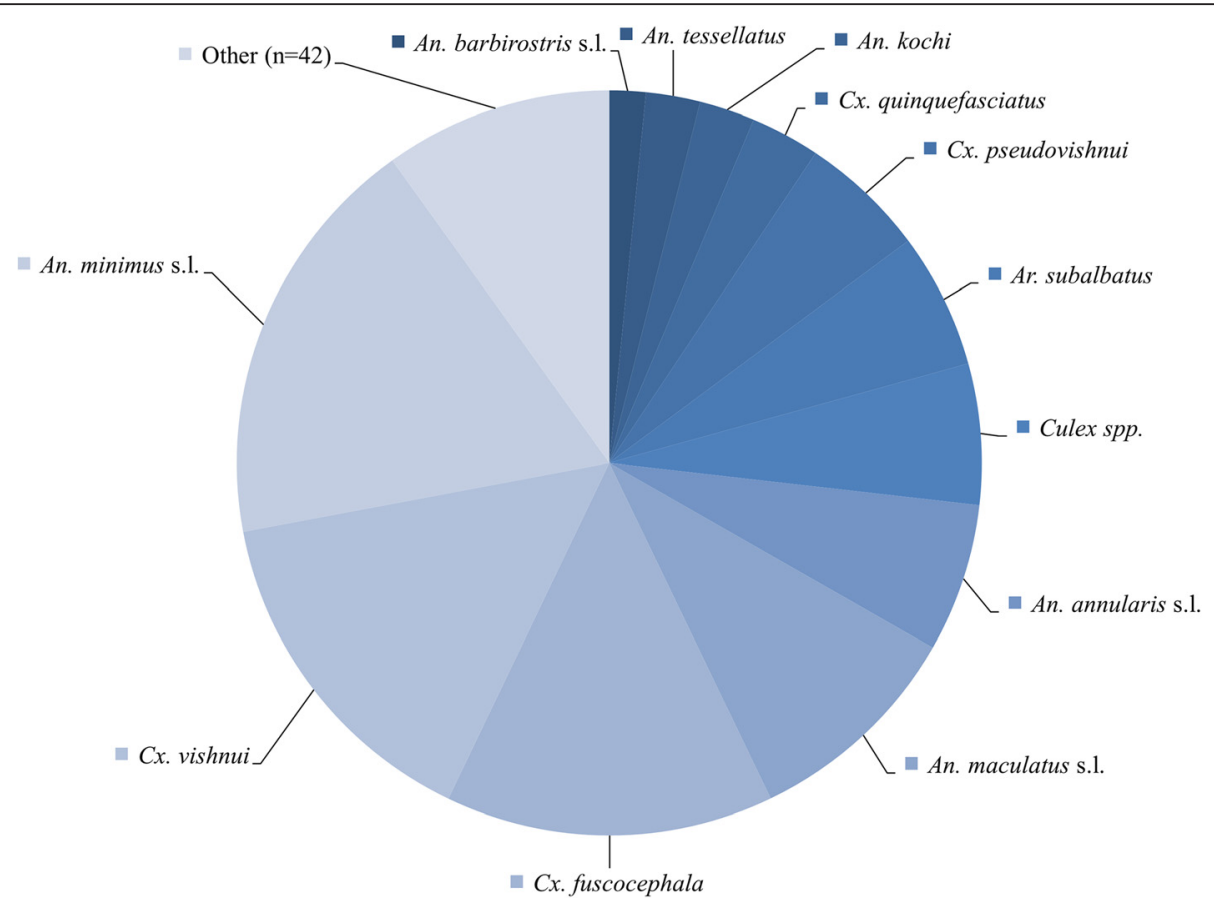

Fig. 3 Schematic representation of the mosquitoes captured in the present study. Species that constituted less than $1 \%$ of the total collected population were summarized as 'other'. A full table of containing all mosquito species is given in the (Additional file 2: Table S1) 
Table 2 Numbers of mosquitoes trapped by CDC-LT, and CDC-LT performance

\begin{tabular}{|c|c|c|c|c|c|c|c|}
\hline & Trap-nights & $\mathrm{n}$ & MTY & $\mathrm{aCRR}$ & $P$ & $95 \% \mathrm{Cl}$ & \\
\hline \multicolumn{8}{|l|}{ Ae. albopictus $(n=68)$} \\
\hline Trap w/o $\mathrm{CO}_{2}$ (reference) & 1280 & 36 & 10 & & & & \\
\hline Trap with $\mathrm{CO}_{2}$ & 1600 & 32 & 7 & 0.81 & 0.52 & 0.41 & 1.56 \\
\hline Indoor trap (reference) & 1655 & 51 & 11 & - & - & - & - \\
\hline Outdoor trap & 1225 & 17 & 5 & 0.53 & 0.07 & 0.27 & 1.05 \\
\hline \multicolumn{8}{|l|}{ Anopheles spp. $(n=2989)$} \\
\hline Trap w/o $\mathrm{CO}_{2}$ (reference) & 1280 & 1157 & 330 & & & & \\
\hline Trap with $\mathrm{CO}_{2}$ & 1600 & 1832 & 418 & 1.39 & 0.04 & 1.01 & 1.61 \\
\hline Indoor trap (reference) & 1655 & 1628 & 359 & - & - & - & - \\
\hline Outdoor trap & 1225 & 1361 & 406 & 0.92 & 0.53 & 0.74 & 1.17 \\
\hline
\end{tabular}

An. annularis s.l. $(n=431)$

Trap w/o $\mathrm{CO}_{2}$ (reference)

1280

$171 \quad 49$

Trap with $\mathrm{CO}_{2}$

$260 \quad 59$

Indoor trap (reference)

1600

260

59

1655

161

Outdoor trap

1225

270

80

1.28

0.37

0.75

2.17

An. maculatus s.l. $(n=641)$

Trap w/o CO 2 (reference)

1280

250

Trap with $\mathrm{CO}_{2}$

1600

Indoor trap (reference)

1655

391

378

Outdoor trap

1225

263

$-$

$-$

$-$

-

An. minimus s.l. $(n=1206)$

Trap w/o $\mathrm{CO}_{2}$ (reference)

1280

Trap with $\mathrm{CO}_{2}$

1600

Indoor trap (reference)

1655

Outdoor trap

1225

Armigeres spp. $(n=404)$

$448 \quad 128$

Trap w/o $\mathrm{CO}_{2}$ (reference)

1280

1600

758

128

Trap with $\mathrm{CO}_{2}$

1655

679

173

527

150

157

0.52

0.60

0.79

1.51

Indoor trap (reference)

1225

159

45

Outdoor trap

245

55

38

174

38

\section{Culex spp. $(n=3094)$}

Trap w/o $\mathrm{CO}_{2}$ (reference)

Trap with $\mathrm{CO}_{2}$

Indoor trap (reference)

Outdoor trap

Cx. quinquefasciatus ( $n=201)$

Trap w/o $\mathrm{CO}_{2}$ (reference)

Trap with $\mathrm{CO}_{2}$ 
Table 2 Numbers of mosquitoes trapped by CDC-LT, and CDC-LT performance (Continued)

\begin{tabular}{|c|c|c|c|c|c|c|c|}
\hline \multicolumn{8}{|l|}{ Cx. vishnui $(n=997)$} \\
\hline Trap w/o $\mathrm{CO}_{2}$ (reference) & 1280 & 280 & 250 & & & & \\
\hline Trap with $\mathrm{CO}_{2}$ & 1600 & 717 & 391 & 1.64 & 0.02 & 1.09 & 2.44 \\
\hline Indoor trap (reference) & 1655 & 446 & 378 & - & - & - & - \\
\hline Outdoor trap & 1225 & 531 & 263 & 0.88 & 0.55 & 0.59 & 1.32 \\
\hline
\end{tabular}

efficacy by seasonality was examined. Better capture rate of Anopheles spp. mosquitoes by $\mathrm{CO}_{2}$ baited traps was restricted to the hot season (March to May, aCRR 1.49, $p=0.04$ ), whereas in the other seasons (rainy and dry), $\mathrm{CO}_{2}$ baited traps were equivalent to non-baited traps $(P=0.30$ and $P=0.88$, respectively). Seasonality did not vary the capture rate difference between indoor and outdoor traps for Anopheles spp. These observations extended to An. minimus s.l.. The other Anopheles species were not abundant enough to fit the interaction model.

Similarly, the effect of better outdoor trapping of Culex spp. in $\mathrm{CO}_{2}$ baited traps was restricted to the hot season (effect measure modification 1.94, $P=0.05$ ). These observations did not hold when only $C x$. vishnui was considered. Armigeres spp. mosquitoes were captured consistently better outdoors and this effect was not modified by seasonality. No effect measure modification was observed for Aedes spp. mosquitoes.

\section{Discussion}

This study evaluated the efficiency of CDC-LT used with or without $\mathrm{CO}_{2}$ baits and placed inside or outside of residential dwellings in northwestern Thailand. This is the first in-depth survey and analysis, seeking to provide some guidelines for CDC-LT-based mosquito trapping studies and surveillance programs in this region of Thailand.

Overall, $\mathrm{CO}_{2}$ baits significantly increased trapping efficiency of Anopheles spp. mosquitoes (approximately $40 \%$ observed increase in aCRR), especially when the traps were placed outside of residential dwellings. Stratification by season revealed that the effect was restricted to observations in the hot-season (March to May). Generally, the most abundant Anopheles species, An. minimus s.l. was captured preferentially in indoor traps, which is likely related to its anthropophilic nature [22]. We therefore conclude that $\mathrm{CO}_{2}$ baits are beneficial when targeting Anopheles spp., as their use may lead to increased capture rates in comparison to non-baited CDC-LT. These findings are consistent with previous studies, which have shown that dry ice baited CDC-LT are a good alternative choice to collect malaria vectors including $A n$. minimus s.l., and An. maculatus s.l. and An. sawadwongporni
Rattanarithikul and Green, respectively [14, 23]. In contrast, previous studies on African and Brazilian malaria vectors, specifically $A n$. arabiensis Patton, An. funestus s.l. Giles, An. darlingi Root, and An. aquasalis Curry have shown that $\mathrm{CO}_{2}$ was insufficiently attractive as a standalone bait and that traps using $\mathrm{CO}_{2}$ in mixed odor baits or together with body odors may provide better results [12, 24, 25]. Most of the collected Anopheles mosquitoes were in the unfed state and feeding status did not seem to impact capture efficiency when comparing indoor and outdoor trap locations. This stands in contrast to a previous study that indicated a preferential capture of bloodfed mosquitoes (Anopheles quadriannulatus (Theobald) and $A n$. funestus s.l.) by CDC-LT in indoor locations in Zambia [26], however this may be attributable to the low numbers of blood fed mosquitoes observed in this study and that the captured Anopheles species commonly exhibit a zoophilic host preference [27].

Culex spp. were the most abundant species collected in this study. Overall, there was no significant difference in the capture efficiency of baited or unbaited traps and/ or trap locations (Table 2). Similar to Anopheles spp. there was a tendency that $\mathrm{CO}_{2}$ baited traps were more efficient than unbaited traps in outdoor locations. When Cx. vishnui was considered separately, capture efficiency was significantly higher in $\mathrm{CO}_{2}$ baited traps. More detailed analysis revealed that this effect was restricted to traps placed outdoors and in the hot season (as compared to unbaited traps placed outdoors in the hot season).

Cx. vishnui is a main vector of Japanese Encephalitis Virus (JEV) $[28,29]$. It is most commonly found in fragmented forest, rural, and suburban habitats and is exophagic in nature, preferentially feeding on pigs [30, 31]. This may explain why it is more frequently trapped in outdoor locations. Previous studies have shown improved collected mosquito numbers in $\mathrm{CO}_{2}$ baited traps for $C x$. quinquefasciatus in French Polynesia [32], and $C x$. quinquefasciatus and $C x$. annulioris Theobald in Kenya [13]. In addition, the use of CDC-LT with dry ice was most effective for trapping of $C x$. quinquefasciatus when compared with UV light traps and gravid traps in China [33]. This effect was not observed in the present study but this may be attributable to the low numbers of 
Cx. quinquefasciatus captured. Traps were mostly placed in villages surrounded by mountains and forests whereas $C x$. quinquefasciatus is a mostly urban mosquito species and known to breed in open drains polluted with organic matter [20,34]. Therefore, the trap setting strategy applied in this study may not have been suitable to capture large numbers of $C x$. quinquifasciatus.

Armigeres mosquitoes (>95\% Ar. subalbatus) were captured consistently better outdoors in the $\mathrm{CO}_{2}$ baited traps and this effect was consistent across seasons. Ar. subalbatus primarily occurs in plantation areas and forests, and is mainly active during the day particularly in the crepuscular period [18]. This may explain its preferential capture in outdoor locations. Ar. subalbatus is known to transmit Wuchereria bancrofti and several zoonotic filarial worms such as Brugia pahangi [35, 36]. While some previous studies have compared captured Ar. subalbatus numbers using different types of traps, we are not aware of a direct comparison of $\mathrm{CO}_{2}$ vs. non$\mathrm{CO}_{2}$ and indoor vs. outdoor trap placements for this mosquito species [37].

Overall, the number of Aedes species mosquitoes captured in this study was low and most captured Aedes mosquitoes were Ae. albopictus. Although previous studies have indicated that CDC-LT are amongst the most efficient traps for the capture of some Aedes species [38] these differences were not apparent for Ae albopictus. $\mathrm{CO}_{2}$ baiting slightly increased Ae. aegypti capture in a comparative trapping study in Manaus [39]. In the present study, there were no statistically significant differences in trapping efficacy with or without $\mathrm{CO}_{2}$ and the placement of the traps. Ae. albopictus seemed to have a tendency of preferential indoor capture $(P=0.07)$. Extended trapping studies would need to be conducted in order to determine whether capture efficiency is improved by $\mathrm{CO}_{2}$ and/or whether indoor/outdoor trap placement is important. Aedes trapping studies commonly use BG traps and it has been shown that these are more effective in capturing Aedes than CDC-LT [40, 41].

This study is limited by several factors. Trap placement was irregular and the number of trap nights differed considerably between villages and months of year (see Additional file 1: Tables S2 and Additional file 3: Table S3). While most previous studies distinguish between traps by counting absolute mosquito numbers, due to the complex and irregular placement of the traps in this study we compared the rate of mosquito capture per unit time, rather than absolute numbers [14, 39]. Although CDC-LT baited with $\mathrm{CO}_{2}$ were shown to increase capture rate for several mosquito species including several important disease vectors (Anopheles spp., Cx. vishnui, Ar. subalbatus), it should be noted that the traps require daily dry ice and battery changes limiting the scope of trapping studies, as each trap needs to be maintained every day. Over $94 \%$ of female mosquitoes in the trapped population were not blood-fed. It is unclear whether these individuals are newly emerged (nulliparous) or parous females that have not yet taken a blood meal. The ratio of nulliparous to parous female mosquitoes (determined e.g., by dissection) may represent an important entomological parameter to be determined in future studies. Normally, An. minimus s.l. and An. maculatus s.l. are regarded as exophilic [42]. A surprisingly small percentage of occupants in the study houses reported using ITNs (40-50\% Thai and $30 \%$ Karen).

We cannot exclude the possibility that concurrent usage of ITN decreased indoor biting, but our analyses did not show such an effect modification, possibly because our sample numbers are too small. Other factors, such as house structures and the presence of domestic animals around houses might further affect mosquito behavior.

Further studies should be conducted to comparatively evaluate whether the species composition, and the blood-fed and physiological age distribution of captured mosquitoes is similar for CDC-LT and human landing catches and thus, if CDC-LT are truly capable of capturing representative samples of those mosquitoes relevant for human disease transmission. This study highlights differences in trapping efficiency of CDC-LT (baited and unbaited) for different mosquito species. Our study thus provides important orientation for more targeted future vector trapping studies on the Thai-Myanmar border, an important cross-border malaria transmission region.

\section{Conclusion}

The present study shows that CDC-LT baited with $\mathrm{CO}_{2}$ generally capture more Anopheles, Culex and Armigeres mosquitoes than unbaited traps, especially when the traps are placed in outdoor locations. When traps were placed in indoor locations, there was little or no difference in baited vs. unbaited CDC-LT. Comparative trapping efficacy also varies with season. The results of the present study provide guidance for future entomological studies for surveillance of the local mosquito vectors in northwestern Thailand and elsewhere.

\section{Additional files}

Additional file 1: Table S2. Trap-nights and mosquitoes caught per trap and year in each of the seven villages for the most abundant Anopheles mosquito species. (DOCX $25 \mathrm{~kb}$ )

Additional file 2: Table S1. All mosquitoes captured in the present study, their blood-fed status, percentage of females and gravidity status. (DOCX $18 \mathrm{~kb}$ )

Additional file 3: Table S3. Trap-nights and mosquitoes caught per trap and year in each of the seven villages for the most abundant mosquito genera and species other than Anopheles. (DOCX $19 \mathrm{~kb}$ ) 


\section{Competing interests}

The authors declare they have no competing interests.

\section{Authors' contributions}

Conceived and designed the study: PS, JS, GY, and LC; Collected data: PS, YS, SS, KK, and AP; Analysed data: SK, PS, and IM; Wrote the manuscript: PS, SK, IM, JS, and LC. All authors read and approved the final version of the manuscript.

\section{Acknowledgements}

This study was supported by grants (U19A1089672 and D43TW006571) from the National Institutes of Health. PS was supported by Asia Pacific Malaria Elimination Network (APMEN) fellowship 2014. SK is supported by an NHMRC Early Career Fellowship (\#1052760). IM is support by an NHMRC Senior Research Fellowship (\#1043345).

\section{Author details}

'Department of Medical Entomology, Faculty of Tropical Medicine, Mahidol University, Bangkok, Thailand. 'Population Health and Immunity Division, Walter and Eliza Hall Institute of Medical Research, Melbourne, Australia. ${ }^{3}$ Program in Public Health, University of California, Irvine, CA, USA. ${ }^{4}$ Department of Entomology, Pennsylvania State University, University Park, PA, USA. ${ }^{5}$ Mahidol Vivax Research Unit, Faculty of Tropical Medicine, Mahidol University, Bangkok, Thailand.

Received: 13 July 2015 Accepted: 23 November 2015 Published online: 15 December 2015

\section{References}

1. Achee NL, Youngblood L, Bangs MJ, Lavery JV, James S. Considerations for the use of human participants in vector biology research: a tool for investigators and regulators. Vector Borne Zoonotic Dis. 2015;15:89-102.

2. Misnistry of Public Health (MOPH), Thailand. Department of Disease Control Annual Report. Nonthaburi: MOPH; 2013.

3. World Health Organization (WHO): Malaria in the Greater Mekong Subregion: regional and country profiles: World Health Organization. In WHO Mekong Malaria Programme; 2010.

4. Cui L, Yan G, Sattabongkot J, Chen B, Cao Y, Fan Q, et al. Challenges and prospects for malaria elimination in the Greater Mekong Subregion. Acta Trop. 2012;121:240-5.

5. Service MW. The need for improved methods for sampling mosquito populations. Wiad Parazytol. 1977;23:203-6.

6. Lima JB, Rosa-Freitas MG, Rodovalho CM, Santos F, Lourenco-de-Oliveira R. Is there an efficient trap or collection method for sampling Anopheles darlingi and other malaria vectors that can describe the essential parameters affecting transmission dynamics as effectively as human landing catches? - A review. Memorias do Instituto Oswaldo Cruz. 2014;109:685-705.

7. Kilama M, Smith DL, Hutchinson R, Kigozi R, Yeka A, Lavoy G, et al. Estimating the annual entomological inoculation rate for Plasmodium falciparum transmitted by Anopheles gambiae s.l. using three sampling methods in three sites in Uganda. Malar J. 2014;13:111.

8. Reisen WK, Meyer RP, Cummings RF, Delgado O. Effects of trap design and $\mathrm{CO}_{2}$ presentation on the measurement of adult mosquito abundance using Centers for Disease Control-style miniature light traps. J Am Mosq Control Assoc. 2000;16:13-8.

9. Becker N, Zgomba M, Petric D, Ludwig M. Comparison of carbon dioxide, octenol and a host-odour as mosquito attractants in the Upper Rhine Valley, Germany. Med Vet Entomol. 1995;9:377-80.

10. Costantini C, Gibson G, Sagnon N, Della Torre A, Brady J, Coluzzi M. Mosquito responses to carbon dioxide in a west African Sudan savanna village. Med Vet Entomol. 1996;10:220-7.

11. Mboera LEG, Takken W. Carbon dioxide chemotropism in mosquitoes (Diptera: Culicidae) and its potential in vector surveillance and management programmes. Rev Med Vet Entomol. 1997;85:55-368.

12. Hiwat H, Andriessen R, Rijk M, Koenraadt CJ, Takken W. Carbon dioxide baited trap catches do not correlate with human landing collections of Anopheles aquasalis in Suriname. Mem Inst Oswaldo Cruz. 2011;106:360-4.

13. Muturi EJ, Mwangangi J, Shililu J, Muriu S, Jacob B, Mbogo CM, et al. Evaluation of four sampling techniques for surveillance of Culex quinquefasciatus (Diptera: Culicidae) and other mosquitoes in African rice agroecosystems. In J Med Entomol. 2007;44:503-8. 2007:503-508.
14. Sithiprasasna R, Jaichapor $B$, Chanaimongkol S, Khongtak $P$, Lealsirivattanakul T, Tiang-Trong S, et al. Evaluation of candidate traps as tools for conducting surveillance for Anopheles mosquitoes in a malaria-endemic area in western Thailand. J Med Entomol. 2004;41:151-7.

15. Zhou G, Sirichaisinthop J, Sattabongkot J, Jones J, Bjornstad ON, Yan G, et al. Spatio-temporal distribution of Plasmodium falciparum and $P$. vivax malaria in Thailand. Am J Trop Med Hyg. 2005;72:256-62.

16. Sattabongkot J, Tsuboi T, Zollner GE, Sirichaisinthop J, Cui L. Plasmodium vivax transmission: chances for control? Trends Parasitol. 2004;20:192-8.

17. Cui L, Yan G, Sattabongkot J, Cao Y, Chen B, Chen X, et al. Malaria in the Greater Mekong Subregion: heterogeneity and complexity. Acta Trop. 2012;121:227-39.

18. Rattanarithikul R, Harbach RE, Harrison BA, Panthusiri P, Coleman RE, Richardson JH. Illustrated keys to the mosquitoes of Thailand. VI. Tribe Aedini. Southeast Asian J Trop Med Public Health. 2010;41 Suppl 1:1-225.

19. Rattanarithikul R, Harbach RE, Harrison BA, Panthusiri P, Coleman RE. Illustrated keys to the mosquitoes of Thailand V. Genera Orthopodomyia, Kimia, Malaya, Topomyia, Tripteroides, and Toxorhynchites. Southeast Asian J Trop Med Public Health. 2007;38 Suppl 2:1-65.

20. Rattanarithikul R, Harbach RE, Harrison BA, Panthusiri P, Jones JW, Coleman RE. Illustrated keys to the mosquitoes of Thailand. II. Genera Culex and Lutzia. Southeast Asian J Trop Med Public Health. 2005;36 Suppl 2:1-97.

21. Rattanarithikul R, Harrison BA, Harbach RE, Panthusiri P, Coleman RE. Illustrated keys to the mosquitoes of Thailand. IV. Anopheles. Southeast Asian J Trop Med Public Health. 2006;37 Suppl 2:1-128.

22. Dav V. Anopheles minimus: Its bionomics and role in tranmsission of malaria in Assam, India. Bulletin of World Health Organization. 1996;74(1): 61-66.

23. Moore SJ, Zunwei D, Hongning Z, Xuezhong W, Hongbing L, Yujiang $X$, et al. The efficacy of different mosquito trapping methods in a forest-fringe village, Yunnan Province, Southern China. Southeast Asian J Trop Med Public Health. 2001;32:282-9.

24. Service MW. Field Sampling Methods. London and New York: Elsevier; 1993.

25. Rubio-Palis Y, Curtis CF. Evaluation of different methods of catching anopheline mosquitoes in western Venezuela. J Am Mosq Control Assoc. 1992:8:261-7.

26. Sikaala CH, Killeen GF, Chanda J, Chinula D, Miller JM, Russell TL, et al. Evaluation of alternative mosquito sampling methods for malaria vectors in Lowland South-East Zambia. Parasit Vectors. 2013;6:91.

27. Rattanarithikul R, Harrison BA, Panthusiri P, Coleman RE. Illustrated keys to the mosquitoes of Thailand I. Background; geographic distribution; lists of genera, subgenera, and species; and a key to the genera. Southeast Asian J Trop Med Public Health. 2005;36 Suppl 1:1-80.

28. Leake CJ, Ussery MA, Nisalak A, Hoke CH, Andre RG, Burke DS. Virus isolations from mosquitoes collected during the 1982 Japanese encephalitis epidemic in northern Thailand. Trans R Soc Trop Med Hyg. 1986;80:831-7.

29. Murty US, SatyaKumar DV, Sriram K, Rao KM, Singh TG, Arunachalam N, et al. Seasonal prevalence of Culex vishnui subgroup, the major vectors of Japanese encephalitis virus in an endemic district of Andhra Pradesh, India. J Am Mosq Control Assoc. 2002;18:290-3.

30. Mwandawiro C, Boots M, Tuno N, Suwonkerd W, Tsuda Y, Takagi M. Heterogeneity in the host preference of Japanese encephalitis vectors in Chiang Mai, northern Thailand. Trans R Soc Trop Med Hyg. 2000;94:238-42.

31. Thongsripong P, Green A, Kittayapong P, Kapan D, Wilcox B, Bennett S Mosquito vector diversity across habitats in central Thailand endemic for dengue and other arthropod-borne diseases. PLoS Negl Trop Dis. 2013;7:e2507.

32. Russell RC. The relative attractiveness of carbon dioxide and octenol in CDC- and EVS-type light traps for sampling the mosquitoes Aedes aegypti (L.), Aedes polynesiensis Marks, and Culex quinquefasciatus Say in Moorea, French Polynesia. J Vector Ecol. 2004;29:309-14.

33. Zhang HL, Zhang YZ, Yang WH, Feng Y, Nasci RS, Yang J, et al. Mosquitoes of Western Yunnan Province, China: seasonal abundance, diversity, and arbovirus associations. PLoS One. 2013;8:e77017.

34. David MR, Ribeiro GS, Freitas RM. Bionomics of Culex quinquefasciatus within urban areas of Rio de Janeiro, Southeastern Brazil. Rev Saude Publica. 2012;46:858-65.

35. Pothikasikorn J, Bangs MJ, Boonplueang R, Chareonviriyaphap T. Susceptibility of various mosquitoes of Thailand to nocturnal subperiodic Wuchereria bancrofti. J Vector Ecol. 2008;33:313-20. 
36. Tan LH, Fong MY, Mahmud R, Muslim A, Lau YL, Kamarulzaman A. Zoonotic Brugia pahangi filariasis in a suburbia of Kuala Lumpur City, Malaysia. Parasitol Int. 2011;60:111-3.

37. Oli K, Jeffery J, Vythilingam I. A comparative study of adult mosquito trapping using dry ice and yeast generated carbon dioxide. Trop Biomed. 2005;22:249-51.

38. Hoel DF, Kline DL, Allan SA. Evaluation of six mosquito traps for collection of Aedes albopictus and associated mosquito species in a suburban setting in north central Florida. J Am Mosq Control Assoc. 2009;25:47-57.

39. Degener CM, Azara TM, Roque RA, Codeco CT, Nobre AA, Ohly JJ, et al. Temporal abundance of Aedes aegypti in Manaus, Brazil, measured by two trap types for adult mosquitoes. Memorias do Instituto Oswaldo Cruz. 2014:109:1030-40.

40. Hapairai LK, Plichart C, Naseri T, Silva U, Tesimale L, Pemita P, et al. Evaluation of traps and lures for mosquito vectors and xenomonitoring of Wuchereria bancrofti infection in a high prevalence Samoan Village. Parasit Vectors. 2015;8:287.

41. Owino EA, Sang R, Sole CL, Pirk C, Mbogo C, Torto B. An improved odor bait for monitoring populations of Aedes aegypti-vectors of dengue and chikungunya viruses in Kenya. Parasit Vectors. 2015;8:253.

42. Sinka ME, Bangs MJ, Manguin S, Chareonviriyaphap T, Patil AP, Temperley WH et al. The dominant Anopheles vectors of human malaria in the Asia-Pacific region: occurrence data, distribution maps and bionomic precis. Parasit Vectors. 2011:4:89.

\section{Submit your next manuscript to BioMed Central} and we will help you at every step:

- We accept pre-submission inquiries

- Our selector tool helps you to find the most relevant journal

- We provide round the clock customer support

- Convenient online submission

- Thorough peer review

- Inclusion in PubMed and all major indexing services

- Maximum visibility for your research 